\title{
EFEKTIVITAS KINERJA MUSYAWARAH GURU MATA PELAJARAN (MGMP) EKONOMI SMA DI KABUPATEN BOYOLALI
}

\author{
Muhammad Sopiyana, Sugiyono \\ Prodi Manajemen Pendidikan,Universitas Negeri Yogyakarta \\ zopiyanayana@yahoo.com, sugiyono_1953@yahoo.com
}

\begin{abstract}
Abstrak
Penelitian ini bertujuan untuk menemukan model pembinaan MGMP Ekonomi SMA di Kabupaten Boyolali terkait dengan kinerja dalam pelaksanaan tugas, fungsi MGMP, dan kesesuaiannya dengan rambu-rambu KKG dan MGMP dari Direktorat Jendral Pendidikan. Metode penelitian adalah metode kualitatif. Hasil penelitian: (1) profil MGMP Ekonomi SMA di Kabupaten Boyolali sudah sesuai dengan rambu-rambu KKG dan MGMP dengan pengembangan pada sisi tugas pokok dan fungsi MGMP, (2) kinerja MGMP Ekonomi SMA di Kabupaten Boyolali belum efektif. (3) hambatan MGMP Ekonomi SMA di Kabupaten Boyolali, yakni: pertama, hambatan internal: jadwal rapat sering berubah, keterlambatan anggota dalam mengahdiri rapat. Kedua, hambatan eksternal, berasal dari sekolah anggota MGMP, yakni: perijinan yang sulit bagi anggota oleh kepala sekolah untuk megikuti rapat. (4) model pembinaan yang terdiri dari dua model yaitu pembinaan untuk mengatasi permasalahan di organisasi MGMP Ekonomi SMA di Kabupaten Boyolali provinsi Jawa Tengah, dan pembinaan dari dalam dan dari luar organisasi MGMP Ekonomi SMA di Kabupaten Boyolali, dan pembinaan organisai MGMP di kabupaten Kampar provinsi Riau yang digambarkan dalam flowcart.
\end{abstract}

Kata kunci: kinerja, MGMP, organisasi

\section{THE EFFECTIVE PERFORMANCE OF THE FSMT OF ECONOMICS AT SHSS IN BOYOLALI REGENCY}

Muhammad Sopiyana, Sugiyono

Prodi Manajemen Pendidikan,Universitas Negeri Yogyakarta zopiyanayana@yahoo.com, sugiyono_1953@yahoo.com

\begin{abstract}
Abstrack
This study aims to investigate: the profile of the Forum of Subject Matter Teachers (FSMT) of Economics at senior high schools (SHSs) in Boyolali Regency, the performance of the FSMT of SHSs in Boyolali Regency, constraints in the task and function accomplishment by the FSMT of Economics at SHSs in Boyolali Regency, and the adopted advancement model for the FSMT of Economics at SHSs in Boyolali.This was a qualitative study. The research findings are as follows: (1) The profile of the FSMT of Economics at SHS in Boyolali Regency has confirmed to the regulations from the Teacher Work Group (TWG) and FMST of the Department of National Education regarding the main tasks and functions of the FSMT; (2) The performance of the FSMT of Economics at SHS in Boyolali Regency is not effective yet; (3) Constraints that the FSMT of Economics at SHSs in Boyolali Regency encounters include: first, internal constraints such as the meeting schedule which is not fixed; and second, external constraints from the schools which are members of the FSMT such as the permit to attend a meeting for the members which is difficult to obtain from the principal. (4) The advancement models comprise two models, namely the one to overcome problems in the organization of the FSMT of Economics at SHSs in Boyolali, Central Java Province, and the advancement from inside and outside of the organization of the FSMT of Economics at SHSs in Boyolali Regency, and the advancement of the organization of the FSMT in Kampar Regency, Riau Province, illustrated in a flowchart.
\end{abstract}

Keywords: performance, FMST, organization 


\section{Pendahuluan}

Perkembangan ilmu pengetahuan dan teknologi berlangsung cepat dan berpengaruh terhadap kehidupan organisasi. Organisasi harus dapat menyesuaikan dengan keadaan dan bahkan harus mengantisipasi perubahan dengan menganalisis kekuatan (strength), kelemahan (weakness) dalam organisasi, memanfaatkan peluang (opportunity), serta mengantisipasi ancaman (threats) yang mungkin dihadapi.

Organisasi yang dinamis selalu mengalami perubahan sebagai akibat perkembangan ilmu pengetahuan dan teknologi. Organisasi dituntut untuk dapat menyesuaikan diri dengan keadaan dan berupaya mengantisipasi perubahan yang akan terjadi di masa depan. Para pemimpin dan anggota organisasi saat ini dihadapkan pada masalah persaingan, menurunnya efektivitas dan peningkatan pelayanan kepada masyarakat.

Masalah-masalah yang dihadapi organisasi pada umumnya juga terjadi pada organisasi pendidikan. Menurut Tilaar 1994, p. 150), masalah pokok dalam sistem pendidikan nasional adalah kualitas pendidikan, relevansi, manajemen pendidikan dan efisiensi sumberdaya pendidikan. Lebih lanjut dikemukakan oleh Tilaar (1994, p. 153) bahwa masalah manajemen pendidikan merupakan salah satu masalah pokok yang menimbulkan krisis dalam dunia pendidikan dewasa ini, dikarenakan ketiadaan tenaga-tenaga administrator pendidikan yang berimbas pada hasil belajar murid, kurangnya motivasi siswa, atau belum penuhnya perhatian orang tua dan kelemahan-kelemahan dipihak guru, tetapi secara meyakinkan juga diperburuk oleh perilaku kepemimpinan yang tidak tepat pakai dan tidak tepat guna.

Dengan demikian untuk mewujudkan tujuan pendidikan, manajemen merupakan faktor penting. Oleh karena itu pendidikan harus dikelola oleh administrator pendidikan yang profesional, dalam arti mampu mendayagunakan sumber daya yang ada dan dapat mengelola keadaan lingkungan serta tuntutan masyarakat yang selalu berkembang. Pembentukan organi- sasi-organisasi pendidikan yang bertujuan meningkatkan kinerja pendidik dari segi kemampuan, pengetahuan, profesinalisme dan produktifitas para pendidik. Kemampuan pengelolaan organisasi diperlukan untuk mengelola organisasi-organisasi pendidikan agar mampu menjalankan tugas dan kinerjanya dengan baik sehingga dapat meningkatkan produktifitas dan profesinalisme para pendidik termasuk dalam permasalahan ini adalah organisasi MGMP Ekonomi SMA di Kabupaten Boyolali.

Organisasi MGMP Ekonomi SMA di kabupaten Boyolali adalah wadah bagi guru untuk saling bertukar pikiran antarsesama guru, mediator, fasilitator/pendamping, dan inovator dalam rangka membantu tugas Dinas Pendidikan yang berkaitan dengan pengembangan, implementasi, monitoring dan evaluasi Program Muatan Lokal dan Kurikulum di berbagai jenis dan jenjang pendidikan. Wadah/organisasi ini adalah salah satu upaya untuk membantu mewujudkan kualitas pendidikan, relevansi, manajemen pendidikan dan efisiensi sumber daya pendidikan yang baik seperti dikemukaan sebelumnya. Apabila terdapat permasalahan berupa adanya kesenjangan antara kinerja MGMP Ekonomi SMA di Kabupaten Boyolali dengan tugas pokok dan fungsi MGMP yang ada di buku panduan maka akan berdampak pada hasil yang diperoleh organisasi MGMP tersebut.

Permasalahan yang terkait dengan peningkatan efektivitas kerja MGMP Ekonomi SMA di Kabupaten Boyolali adalah belum optimalnya tugas dan fungsi yang dijalankannya. Organisasi MGMP tersebut juga mempunyai tujuan membantu mewujudkan pendidik yang berkualitas. Oleh karena itu MGMP sebagai wadah bagi pendidik untuk saling bertukar pikiran diasumsikan dapat memecahkan problematika dalam pelaksanaan pendidikan baik dari segi implementasi, pengembangan, monitoring dan evaluasi guna menciptakan pendidikan yang berkualitas. Oleh karena itu, dibutuhkan peningkatan efektivitas kerja MGMP agar permasalahan yang timbul dapat teratasi dengan baik. Selain itu, permasalahan lain yang timbul adalah adanya 
hambatan dalam pelaksanakan tugas dan fungsi dari MGMP tersebut.

\section{Metode Penelitian}

Metode penelitian yang digunakan dalam penelitian ini adalah pendekatan kualitatif. Penelitian ini dilakukan di tempat perkumpulan rutin MGMP Ekonomi SMA di Kabupaten Boyolali. Peneltian dilaksanakan pada bulan Oktober 2013 Oktober 2014. Penelitian ini berlangsung selama 13 bulan. Alasannya karena rapat MGMP dilaksanakn selama 3 kali dalam 1 semester.

Subjek penelitian adalah Ketua MGMP Kabupaten Boyolali, Pengurus MGMP Kabupaten Boyolali, Anggota MGMP Kabupaten Boyolali. Objek penelitian adalah kinerja MGMP Ekonomi SMA di Kabupaten Boyolali yang meliputi tugas pokok dari MGMP, fungsi MGMP, dan kesesuaian antartugas pokok dan fungsi MGMP yang ada di buku panduan dengan tugas pokok dan funngsi MGMP yang dilakukan oleh anggota MGMP Ekonomi SMA di Kabupaten Boyolali.

Teknik pengumpulan data adalah langkah yang paling penting dalam penelitian karena tujuan utama dari penelitian adalah mendapatkan data. Tanpa mengetahui teknik pengumpulan data, maka peneliti tidak akan mendapatkan data yang memenuhi standar dan yang ditetapkan. Dengan demikian untuk mendapatkan data-data yang terkait dengan tema penelitian digunakan beberapa teknik pengumpulan data sebagai berikut: Observasi, Wawancara, Dokumentasi

Instrumen pengumpulan data dalam penelitian kualitatif adalah peneliti itu sendiri yang menggunakan instrumen pendukung berupa pedoman wawancara, pedoman observasi dan pedoman dokumen.

Analisis Data Suatu penelitian sangat diperlukan analisis data yang berguna untuk memberikan jawaban terhadap permasalahan yang diteliti. Analisis data dalam penelitian ini menggunakan metode kualitatif. Pengertian analisis data adalah proses mencari dan menyusun data secara sistematis yang diperoleh dari hasil wawancara, catatan lapangan, dan dokumentasi, dengan cara mengorganisasikan data kedalam kategori, menjabarkan kedalam unit-unit, melakukan sintesa menyusun kedalam pola, memilih mana yang penting dan yang mana di pelajari, dan membuat kesimpulan sehingga mudah difahami oleh diri sendiri dan orang lain.

Analisa data adalah proses mengatur urutan data, mengorganisasikan ke dalam suatu pola, kategori dan satuan uraian dasar. Sedangkan metode kualitatif merupakan prosedur penelitian yang menghasilkan data deskriptif berupa katakata tertulis atau lisan dari orang orang dan perilaku yang dapat diamati.

Proses analisis data terhadap komponen-komponen utama yang harus benarbenar dipahami. Komponen tersebut adalah reduksi data, kajian data dan penarikan kesimpulan atau verifikasi. Untuk menganalisis berbagai data yang sudah ada digunakan metode deskriptif analitik. Metode ini digunakan untuk menggambarkan data yang sudah diperoleh melalui proses analitik yang mendalam dan selanjutnya diakomodasikan dalam bentuk bahasa secara runtut atau dalam bentuk naratif. Analisis data dilakukan secara induktif, yaitu dimulai dari lapangan atau fakta empiris dengan cara terjun ke lapangan, mempelajari fenomena yang ada di lapangan. Analisis data dalam penelitian kualitaif dilakukan secara bersamaan dengan proses pengumpulan data.

\section{Hasil Penelitian}

Profil Organisasi MGMP Ekonomi SMA di Kabupaten Boyolali

Musyawarah Guru Mata Pelajaran (MGMP) merupakan suatu forum/wadah kegiatan profesional guru mata pelajaran yang berada pada satu gugus sekolah, wilayah kecamatan atau kabupaten/kota. Mengingat bahwa posisi sekolah adalah ujung tombak pembaharuan pendidikan yang esensinya adalah otonomi sekolah, maka pengelolaan pembelajaran sepenuhnya diserahkan kepada guru/sekolah. Oleh 
karena itu peran dan fungsi MGMP menjadi sangat penting dan MGMP harus menjadi agen pembaharuan dalam pembelajaran sehingga pembelajaran menjadi lebih efektif dan menyenangkan.

Perubahan paradigma proses pembelajaran dari mengajar (teaching) menjadi belajar (learning) dan dari teacher centered menjadi student centered menuntut kerja keras pada tenaga kependidikan untuk memberikan pendidikan yang terbaik kepada anak didik, untuk mampu mengembangkan diri dan siap terjun ke masyarakat. Dahulu guru sebagai satu-satunya sumber informasi, tetapi sekarang guru diharapkan lebih banyak berperan sebagai fasilitator.

Dengan adanya perkembangan kurikulum, perlu adanya pemahaman atau persepsi yang sama untuk pelaksanaannya, sehingga diperlukan pertemuan MGMP agar pelaksanaan kegiatan belajar mengajar dapat berjalan dengan lancar. Selain dari pada itu perlu adanya peningkatan SDM yang sesuai dengan tuntutan jaman, mulai dari program pembelajaran sampai dengan penggunaan media pembelajaran atau pengembangan bahan ajar dengan menggunakan Tehnologi Informatika dan Komunikasi (TIK).

Sebelum melangkah lebih dalam lagi mengenai oraganisasi MGMP Ekonomi SMA di Kabupaten Boyolali, terlebih dahulu melihat sekilas sejarah berdirinya oraganisasi MGMP Ekonomi SMA di Kabupaten Boyolali bedasarkan data dan dokumen yang diperoleh peneliti di lapangan. Berdasarkan data dan dokumen yang diperoleh peneliti di lapangan akan dijelasakan mengenai anggran rumah tangga, kegiatan, fungsi dan tugas dari dari organisasi MGMP Ekonomi SMA di Kabupaten Boyolali.

\section{Pelaksanaan Tugas Pokok}

Memberikan Motivasi kepada Guru untuk Mengikuti Kegitan dalam Organisasi

Memotivasi para nggotanya organisasi MGMP Ekonomi SMA di Kabupaten Boyolali mempunyai beberapa cara yaitu dengan mengajak para anggota untuk me- nyusun dan menyempurnakan kegiatan yang disusun oleh para pengurus MGMP, baik penyususnan kegiatan yang sudah direncanakan maupun kegiatan yang sifatnya insidental. Kemudian dilanjutkan dengan melaksanakan kegiatan yang sudah direncanakan tersebut secara bersama. Tujuan dari kegiatan tersbut adalah agar anggota ikut serta dalam mengembangkan organisasi yang dinaunginya dan juga dapat mengembangkan dirinya melalui kegiatan yang di lakukan bersama-sama yang menyangkut organisasi. Kegiatan yang kedua dengan memebrikan pelatihan, pelatihan ini dengan memberikan row material kepada para anggota MGMP Ekonomi SMA di Kabupaten Boyolali, kemudian row material tadi didiskusikan bersama untuk di kembangkan menjadi materi pembelajaran. Dalam diskusi tersebut ketika anggota mengalami permasalahan dapat di bantu dan di diskusikan bersama sehingga dengan berdiskusi bersama para anggota bisa mengeriti dan bisa memecahkan permasalahan yang ada dalam pengembangan bahan ajar atau row material.

\section{Meningkatkan Kemampuan dan Kemahiran Guru dalam Melaksanakan KBM}

Dalam meningkatkan kemapuan dan kemahiran guru untuk melaksanakan KBM organisasi MGMP Ekonomi SMA di Kabupaten Boyolali sudah mengadakan pelatihan-pelatihan yang sudah terprogram di dalam program kerja MGMP. Observasi dan pengamatan yang ketiga pada (Rabu, 07-05-2014) juga menemukan pelatihan mengenai pokok bahasan dala mata pelajaran ekonomi yang hampir semua guru kurang mengerti akan materi tersebut yaitu materi perbankkan tentang pembayaran. Organisasi MGMP Ekonomi SMA di Kabupaten Boyolali mensiasatinya dengan mengadakan workshop tentang materi tersebut dengan mendatangkan pemateri dari luar.

\section{Pelayanan Konsultasi KBM}

Dalam melayani konsultasi kepada anggotanya dengan prinsip membantu apa yang dibutuhkan oleh anggota baik materi ataupun sarana dan prasarana untuk me- 
nunjang KBM di kelas, mengenai pemberian pelayanan konsultasi tentang $\mathrm{KBM}$ organisasi MGMP Ekonomi SMA di Kabupaten Boyolali memberikan fasilitas yang baik. Pelayanan konsultasi di bagi menjadi dua bagian yang pertama konsultasi yang sifatnya umum, konsultasi yang sifatnya umum diberikan kepada seluruh anggota dengan contoh dalam konsultasi penyusunan materi ajar di awal tahun pelajaran, kemudian pendalaman materi di tahun ajaran baru, hal tersebut sering dilakukan oleh organisasi MGMP Ekonomi SMA di Kabupaten Boyolali karena di awal pembelajaran baru anggota sering mengalami kesulitan dalam pengembangan dan pendalaman materi pembelajaran. Maka kegiatan tersebut di lakukan bersama dalam watu yang sudah ditentukan, diharapkan dengan di lakuakn penjelasan dan diskusi bersama semua anggota, anggota dapat mengerti tentang pengembangan dan pendalaman bahan ajar. Kemudian pelayanan konsultasi yang bersifat individu, pelayanan yang bersifat individu biasanya tidak semua anggota mengalami dan diberi konsultasi individu, dengan contoh penyusunan PTK untuk kenaikan pangkat. Tidak semua anggota membuat PTK hanya 1 atau 2 orang, karena berkaitan dengan masalah individu hal ini di masukkan dalam pelayanan konsultasi yang sifatnya individu. Untuk menyikapai solusi yang di berikan oleh organisasi MGMP Ekonomi SMA di Kabupaten Boyolali para anggota bervariatif kebanyakan merasa senang karena permasalahan yang mereka hadapi dapat di pecahkan dan mendapat bantuan dari organisasi MGMP Ekonomi SMA di Kabupaten Boyolali.

Menunjang Pemenuhan Kebutuhan Guru yang Berkaitan dengan KBM, Khususnya yang Menyangkut Materi Pelajaran, Metodologi, Sistem Evaluasi, dan Sarana Penunjang

Untuk memenuhi penunjang materi pembelajaran bagi para guru organisasi MGMP Ekonomi SMA di Kabupaten Boyolali melakukannya dengan pendalaman materi, pendalaman materi yang dimaksud dengan memeberikan pelatihan-pelatihan pembahasan soal ujian nasional, soal olimpiade ekonomi, penyususnan modul, penyususuna lks, penyususna soal ukk, yang dilakukan secara bergilir dalam penyusunannya. MGMP melakukan penyamaan bu$\mathrm{ku}$ panduan antara semua nggota MGMP agar semua anggota dalam penyampean materi dapa merata antara sekolah satu dengan yang lain. tidak itu saja organisasi MGMP guna memenuhi kebutuhan para nggotnya juga melakukan pendalaman materi baru seperti pelatihan tentang materimateri baru di karenakan di kurikulum baru ini banyak materi baru yang bermunculan sehingga banyak anggota yang kurang mengetahui sehingga mgmp mengadakan pelatihan tentang materi baru tersebut contohnya seperti materi ojk, perbankkan, pajak, dll. hal ini bertujuan untuk menambah pengetahuan dan pendalaman pengetahuan tentang materi-materi pembelajaran Ekonomi bagi para anggota MGMP Ekonomi SMA di Kabupaten Boyolali.

Menyebarkan Informasi tentang Kebijakan yang Berkaitan dengan Usaha-Usaha Pembaharuan Pendidikan Dibidang Kurikulum, Metodologi, Sistem Evaluasi, dan Melaporkan Hasil Kegiatan MGMP Serta Menetapkan tindakan Lanjutan

Menyebarkan informasi dulu memakai surat yang di edarkan oleh humas ke sekolah-sekolah dan juga dengan pembagian wilayah sekolah, tapi setelah ada internet dan pesan singkat kita undang pake pesan singkat dan juga untuk men-download surat undangan, di donwload lewat blog. Kemudian ada informasi yang sifatnya mendadak dengan contoh informasi dari dinas yaitu tentang sertifikasi. Informasi teresbut harus segera di kirimkan kepada para anggota, agar cepat dalam mengrimkannya kita melalui pesan singkat saja. Tapi bila ada informasi dari dinas yang sifatnya tidak mendadak disampekan saat rapat berlangsung, dengan contoh kurikulum 2013 dengan menjelasakan informasinya kepada anggota dengan mengundang nara sumber dari luar dari deppora selama 3 minggu berturut yang di lakukan pada tanggal 18 september, 25 september, dan 2 
oktober 2014 hal ini kita adakan rapat hanya untuk meneruskan dan mendapat penjelasan mengenai kurikulum 2013, sehingga dalam menjelasakan informasi tersebut kita mengundang pakarnya langsung sehingga kita dapat mengetahui dengan jelas mengenai info tadi baik dari segi kurikulum, metodologi, evaluasi.

\section{Fungsi MGMP}

Menyusun Program Jangka Panjang, Jangka Menengah dan Jangka Pendek, Serta Mengatur Jadwal dan Kegiatan Secara Rutin

Dalam merancang program MGMP Ekonomi SMA di Kabupaten Boyolali dirancang dahulu oleh pengurus, kemudian perancangan program di bedakan menjadi dua yaitu program jangka pendek dan jangka panjang. Kemudian setelah rancangan kedua progran selesai, program di bawa kedalam forum untuk dimintakan pendapat atau masukan dari para anggota. Kegiatan ini di lakukan agar semua anggota mengetahui program yang akan di jalankan, lebih lannjut mereka juga ikut berpartisipasi dalam menyusun program tersebut. Setelah semua tersusun dan di setujui semua anggota kemudian program di jalankan, program yang dijalankan adalah program jangka pendek terlebih dahulu seperti penyususna soal UAS dan UKK setelah pelaksanaan program jangka pendek dilanjutkan dengan pelaksanaan program jangka panjang seperti mengadakan kunjungan belajar

Memotivasi Para Guru Untuk Megikuti Kegiatan MGMP Secara Rutin Baik Ditingkat Sekolah, Wilayah, Maupun Kota

Memotivasi para anggotanya dapat dilihat dari hasil wawancara yang sudah diverifikasi, responden menyatakan bahwa dalam memotivasi para anggota agar selalu ikut kegiatan dengan memberikan himbauan agar selalu mengikuti perkembangan terbaru di dunia pendidikan melalui kegiatan-kegiatan yang diadakan oleh pemerintah terutama kenmendikbud. Kemudian dengan memberikan informasi terbaru mengenai pendidikan di daerah Boylolali, bila ada seminar atau workshop selalu diberitahu melalui pesan singkat atau melalui blog MGMP. Tidak itu saja dalam kegiatan atau dalam rapat MGMP Ekonomi SMA di Kabupaten Boyolali dengan menghadirkan hal baru sehingga para anggota selalu antusias dalam mengikuti peretemuan MG$\mathrm{MP}$, hal baru tersebut seperti mendatangkan pembicara dari luar kemudian juga kita menjalin kerja sama dengan instansi luar kita undang mereka dan mereka menanggapinya dengan senang hati dan mereka hanya meminta koordinir anggota dan peserta dan semua di tanggung oleh kantor yang bersangkutan, karena mereka sudah ada anggaran untuk bersosialisasi, kemaren waktu masalaha perbankkan kita kerja sama dengan bank BRI untuk menjelaskan materi tentang alat pembayaran dan antusiasme mereka sangat tinggi. Kemudian dengan kunjungan belajar ke UTY untuk si mulasi bursa.

Meningkatkan Mutu Profesionalisme Guru dalam Perencanaan, Pelaksanaan, dan Pengujian/Evaluasi Pembelajaran di Kelas, Sehingga Mampu Meningkatkan dan Pemerataan Mutu Pendidikan Disekolah

Meningkatkan mutu profesionalisme dahulu dituntut secara pribadi dalam mengembangkan potensi dirinya. Hal ini dikarenakan adanya portofolio tapi sekarang ini sudah di ganti dengan sertifikasi, kemudian peningkatan profesionalisme guru di fokuskan pada kelompok-kelompok mata pelajaran yang disebut MGMP. Dengan adanya MGMP guru dituntut untuk mengembangkan dirinya bersama dengan anggota lainnya di dalam organisasi untuk mengembangkan profesionalitasnya dengan mengikuti pelatihan, workshop seperti pelatihan pembuatan SILABUS ke dalam RPP dan juga mengadakan seminar tentang kurikulum, metode pembelajaran, dan evaluasi, kemudian hal yang dibahas saat ini adalah tentang kurikulum baru 2013 tentang penyusunan Silabus ke dalam RPP, Materi, model evalusia, dan juga pelatihan pembuatan media pembelajaran dengan meberikan contoh pembuatan media pembelajaran seperti praktek model pembel- 
ajaran yang pernah di lakukan adalah praktik model pembelajaran cikso dan lesson study, dan juga cara menggunakan sarana dan prasarana seperti menggunakan LCD, pengenalan internet dan lainlain. Kemudian pelatihan pembuatan penelitian tindakan kelas hal ini di berika untuk melatih para guru dalam mengejar kenaikan pangkat karena seorang guru bila ingin naik pangakat harus memiliki kekaryaan seperti penulis buku atau pembuatan PTK. Kegiatan tersebut dilakuak untuk meningkatkan profesionalisme guru hal ini tidak direncanakan secara rutin tapi setiap tahun selalu dilakukan

Mengembangkan Program Supervisi Akademik Klinis yang Berkaitan dengan Pembelajaran yang Efektif

MGMP tidak mempunyai kewenangan sampai disitu karena MGMP itu hanya mendiskusikan masalah pendidikan yang sudah dibatasi dengan mapel tertentu. Untuk melakukan Supervisi sudah ada temaptanya dan bagiannya sendiri yaitu kepala sekolah masing-masing, LPMP dan pengawas karena mereka mempunyai hak untuk mensupervisi. Tapi bila MGMP itu sendiri namanya bukan supervisi melainkan koordinator, kordinator ini di ambil dari anggota MKKS yang mengkoordinator MGMP bagaimana jalannya MGMP, tentang ketercapean tugas MGMP, kemudian mengenai kegiatan apa saja yang dilakukan MGMP, MGMP tersebut harus melaporkan kepada coordinator.

Mengembangkan Silabus dan Melakukan Analisis Materi Pelajaran, Progam Tahunan, Program Semester, Satuan Pelajaran dan Rencana Pembelajaran

Belum pernah dilakukan MGMP Ekonomi SMA di Kabupaten Boyolali memusyawarah tentang kesulitan materi pembelajaran yang kemudian dicarikan jalan keluarnya, menyikapi hal baru tentang mapel Ekonomi dan MGMP ini sifatnya mebantu dan memfasilitasi anggota mengenai kesulitan dan memusyawarahkan informasi tentang berita atau informasi baru dari dunia pendidikan seperti sertifi- kasi, kurikulum, pelatihan, diklat. Mengenai analisis ulanga kegiatan, MGMP tidak mempunyai kewenangan sampe untuk menganalisis ulang, yang ada dalam organisasi MGMP Ekonomi SMA di Kabupaten Boyolali hanyalah melaporkan hasil kegiatan kepada para anggota bila sudah seleseai melaksanakan kegiatan MGMP seperti pertemuan rutin, workshop dan kunjungan belajar.

Sarana Pengembangan Inisiatif dan Inovasi dalam Rangka Peningkatan Mutu Pembelajaran Melalui Berbagai Cara seperti Diskusi, Seminar, Lokakarya dsb

Kegiatan lokakarya dilakukan karena ada dua hal yang pertama karena mendapat bantuan dari PEMKAB untuk mengadakan lokakraya sehinga harus mengadakan lokakarya batuan tersebut berujud dana batuan, kegiatan lokakarya dilakukan dengan kunjungan seperti ke pasar modal UTY. Kemudian yang kedua wujudnya kunjungan belajar hal seperti itu bisa dilakukan karena mendapat batuan atau kerja sama dengan instasi luar seperti yang di lakukan oleh Bank BI yang mengundang MGMP Ekonomi SMA di Kabupaten Boyolali untuk mengikuti workshop di Bank Bi cabang Solo, hal ini bertujuan untuk mengembangkan dan menambah wawasan bagi para anggotanya agar inisiatif dan inofatifnya berkemabang dalam kegiatan pembelajaran di kelas sehingga bila mereka berkembang maka pembelajaran di kelas akan bertambah fariatif

Merumuskan Model Pembelajaran yang Variatif dan Alat-Alat Peraga Praktik Pembelajaran Program Life Skill

Organisasi MGMP Ekonomi SMA di Kabupaten Boyolali memang tidak mengembangakan model pembelajaran melainkan hanya mempraktekkan model pembelajaran yang ada, kemudian yang dilakukan oleh MGMP Ekonomi SMA di Kabupaten Boyolali dalam mempraktekkan model pembelajaran dengan beberapa tahapan yaitu dengan memulai dari pendalaman materi, kemudian pengembangan bahan ajar dan dilajutkan dengan pem- 
bahasan model pembelajaran. Pelatihan dilakukan dengan workshop, pelatihan langsung tentang pengembangan Silabus dan RPP, kemudian pengembangan bahan ajar dengan pengemabngan row material yang dikembangkan ke dalam bahan ajar seperti kisi-kisi pelajaran yang di kembangakan menjadi materi pelajaran, dan pelatihan model pembelajaran yang dilakukan oleh MGMP Ekonomi SMA di Kabupaten Boyolali sepeti palatihan model pembelajaran cikso dan lesion study hal ini dilakukan guna mengembangkan pengetahuan para anggota dalam pengembangan model pembelajaran yang fariatif

Melaporkan Hasil Kegiatan MGMP Secara Rutin Setiap Semester Kepada Dinas Pendidikan atau Depag

Dalam melaporkan kegiatan ke Dinas, dulu masih menggunakan sistem catur wulan. Laporan harus rutin disampaikan ke Dinas tiap catur wulan guna memperoleh sertifikasi guna menunjang portovolio. Dewasa ini, MGMP tidak pernah membuat laporan tersebut setelah otonomi sekolah. Laporan dibuat jika ada kegiatan resmi dari Dinas saja. Dapat di egaskan dalam hal ini MGMP Ekonomi SMA di Kabupaten Boyolali tidak pernah membuat laporan rutin MGMP yang ditunjukkan ke Dinas Pendidikan dan Depag. Hal ini di karenakan MGMP Ekonomi SMA di Kabupaten Boyolali tidak mempunyai atasan. Bisa dilihat secara struktural MGMP tidak mempunyai atasan, laporan yang dibuat oleh MGMP hanya laporan yang sifatnya evaluasi kegiatan dan dilaporkan dalam kegiatan rutin pada anggota

Hambatan-Hambatan dalam Pelaksanaan Tugas dan Fungsi MGMP Ekonomi SMA di Kabupaten Boyolali

Keterlambatan anggota menghadiri mengakibatkan mundurnya rapat, perbedaan persepsi antara anggota yang mengakibatkan perselisihan antarteman. Hal tersebut dikarenakan para anggota tidak mendasarkan pada landasan yang jelas saat berpendapat dan hanya mementingkan diri sendiri. Anggota bersifat pasif dalam rapat sehingga kurang berkembang dan hanya mengandalkan pengurus. Kemudian hambatan datang dari sekolah setiap anggota, kepala sekolah melarang datang untuk rapat dikarenakan yang bersangkutam memiliki tanggung jawab di sekolahnya. Alasan lainnya adalah biaya. Sekolah tidak mau mengirimkan gurunya karena merasa terbebani biaya.

\section{Mekanisme Pembinaan agar MGMP Ekonomi SMA di Kabupaten Boyolali}

Dalam penyelesaian permasalahan yang ada, seperti: datang terlambat, kurangnya perhatian anggota, anggota yang kurang aktif, dan karangan dari sekolah untuk mengikuti rapat, MGMP Ekonomi SMA di Kabupaten Boyolali hanya bisa menghimbau kepada para anggota untuk selalu datang dalam rapat, MGMP Ekonomi SMA di Kabupaten Boyolali tidak memiliki kewenangan untuk meamaksa para anggota untuk selalu datang rapat karena MGMP merupakan organisasi musyawarah guru mata pelajaran. Kemudian bila menemui permasalahan yang sulit, MGMP mempunyai tahapan dalam penyelesaiannya yaitu dengan mencari sumber permasalahan yaitu dengan didiskusikan bersama para pengurus. Setelah mengetahui sumber permasalahannya dirundingakan jalan alternatif keluarnya. Kemudian pengurus membawa topik ke dalam forum untuk dirundingkan bersama anggota tentang alaternatif penyelesaiannya. Hal ini dilakukan agar anggota mengetahui dan ikut bertanggung jawab atas masalah yang dihadapi oleh organisasi sehingga permasalahan tidak dibebankan kepada pengurus saja melainkan anggota juga ikut berpartisipasi dalam penyelesaian permasalahan yang dihadapi oleh anggota maupun organisasi MGMP Ekonomi SMA di Kabupaten Boyolali. Pembinaan untuk meningkatkan kinerja dan peforma anggota untuk melaksanakan tugas dilakukan dengan dua cara yaitu pembinaan dari dalam organisasi tersebut dan pembinaan dari luar organisasi. Pembinaan yang dilakukan oleh Dinas Provinsi adalah langsung turun ke organisasi MGMP tidak melalui Dinas 
Kabupaten. Kemudian organisasi menindaklanjuti dengan mengirimkan anggotanya untuk mengikuti pelatihan. Aggota yang sudah mengikuti pelatihan bertugas untuk memberikan pelatihan kepada para anggotanya

\section{Simpulan dan Saran}

Simpulan

Berdasarkan uraian yang telah disampaikan, maka penelitian menghasilkan beberapa kesimpulan sebagai berikut.

Pertama, profil dari MGMP Ekonomi SMA di Kabupaten Boyolali sudah sesuai standart peraturan dan rambu-rambu KKG dan MGMP dari direktorat jendral pendidikan nasional dengan pengembangan pada sisi tugas pokok dan fungsi yang disesuaikan dengan situasi dan kondisi.

Kedua, pelaksanaan kinerja MGMP Ekonomi SMA di Kabupaten Boyolali dilihat dari pelaksanaan tugas dan fungsi yang sudah dilaksanakan dengan baik, karena sudah menjalankan tugas dan fungsi sesuai dengan tugas dan fungsi dari MGMP. Meskipun MGMP Ekonomi SMA di Kabupaten Boyolali tidak membuat prencanaan tugas pokok, akan tetapi diganti dengan perencana program kerja, rencana program kerja yang disusun MGMP Ekonomi SMA di Kabupaten Boyolali sudah sesuai dengan tugas dari MGMP. Mengenai fungsi yang dijalankan oleh MGMP Ekonomi SMA di Kabupaten Boyolali kurang efektif karena dari 8 fungsi MGMP Ekonomi SMA di Kabupaten Boyolali hanya menyusun dan menjalankan 5 fungsi.

Ketiga, Hambatan pelaksanaan tugas dan fungsi MGMP dibagi menjadi dua yaitu: pertama, hambatan yang berasal dari dalam yang meliputi: (1) jadwal rapat yang sering berubah tidak sesuai jadwal; (2) ketidaktepatan para anggota dalam menghadiri rapat MGMP; (3) perbedaan pendapat antara sesama anggota MGMP ketika rapat atau diskusi; (4) anggota bersifat pasif dalam rapat dan hanya mengandalkan ketua dan para pengurus lainnya; dan (5) sarana dan prasarana penunjang kegiatan MGMP yang kurang. Kedua hambatan dari luar adalah datang dari sekolah setiap anggota peserta MGMP Ekonomi SMA di Kabupaten Boyolali yang tidak di berikan izin oleh kepala sekolah dalam mengikuti rapat rutin MGMP.

Keempat, tahapan pembinaan yang dilakukan oleh dinas kepada MGMP Ekonomi SMA di Kabupaten Boyolali dibedakan menjadi dua bagian yaitu pembinaan yang dilakuakan dari organisasi tersebut.

Saran

Program Pascasarjana UNY

Sebaiknya pengembangan penelitian dan teori di bidang manajemen pendidikan wilayah organisasi lebih dikembangkan agar menghasilkan temuan dan referensi pengembangan bagi teori manajemen pendidikan di bidang organisasi pendidikan yang berbentuk organisasi formal di lingkungan dinas pendidikan Provinsi Jawa Tengah.

Organisasi MGMP Ekonomi SMA di Kabupaten Boyolali

Organisasi MGMP Ekonomi SMA di Kabupaten Boyolali sebaiknya melaksanakan semua tugas dan fungsi MGMP, apabila ingin mengembangakan tugas dan fungsi MGMP sebaiknya di lakuakan sesuai dengan rambu-rambu KKG dan MGMP sehingga tujuan dari MGMP tidak keluar jalur.

\section{Peneliti}

Penelitian tentang kinerja organisasi di lingkungan pendidikan khususnya MGMP Ekonomi SMA di Kabupaten Boyolali dapat di kembangkan lebih luas tidak hanya MGMP melainkan semua organisasi kependidikan yang ada di instansi pemerintahan atau noninstansi pemerintahan.

\section{Dafatar Pustaka}

Tilaar, H., A., R. (1994). Manajemen pendidikan nasional: kajian pendidikan masa depan. Bandung: Penerbit PT Remaja Rosdakarya. 